\title{
CORRECTION
}

\section{Correction to: Paediatric intensive care admission blood pressure and risk of death in 30,334 children}

\author{
A. Matettore ${ }^{1 *}$ (D) S. Ray ${ }^{1,2}$, D. A. Harrison 3 , T. Brick ${ }^{4}$, D. Macrae ${ }^{5}$, M. J. Peters ${ }^{1,2}$ and D. P. Inwald ${ }^{6}$
}

(C) 2019 Springer-Verlag GmbH Germany, part of Springer Nature

\section{Correction to: Intensive Care Med} https://doi.org/10.1007/s00134-019-05638-6

The authors of the article entitled "Paediatric Intensive Care admission blood pressure and risk of death in 30,334 children" inform that due to an error in their database extraction, the following corrections to the data published should be notified:

1. The sentence 'Data were available for 30,334 children between 2004 and 2018.' should read 'Data were available for 34,916 children between 2004 and 2018'.
2. The sentence:'The lowest risk of mortality was at $70 \mathrm{mmHg}$ in the $<2$-year-old cohort, and $95 \mathrm{mmHg}$ in the $\geq 2$-year-old cohort (Fig. 1)'. should read 'The lowest risk of mortality was at $86 \mathrm{mmHg}$ in the $<2$-year-old cohort, and $98 \mathrm{mmHg}$ in the $\geq 2$-year-old cohort (Fig. 1).'

3. Figure 1 has been corrected accordingly and replaced with the figure below:

Full author information is available at the end of the article

\section{Springer}



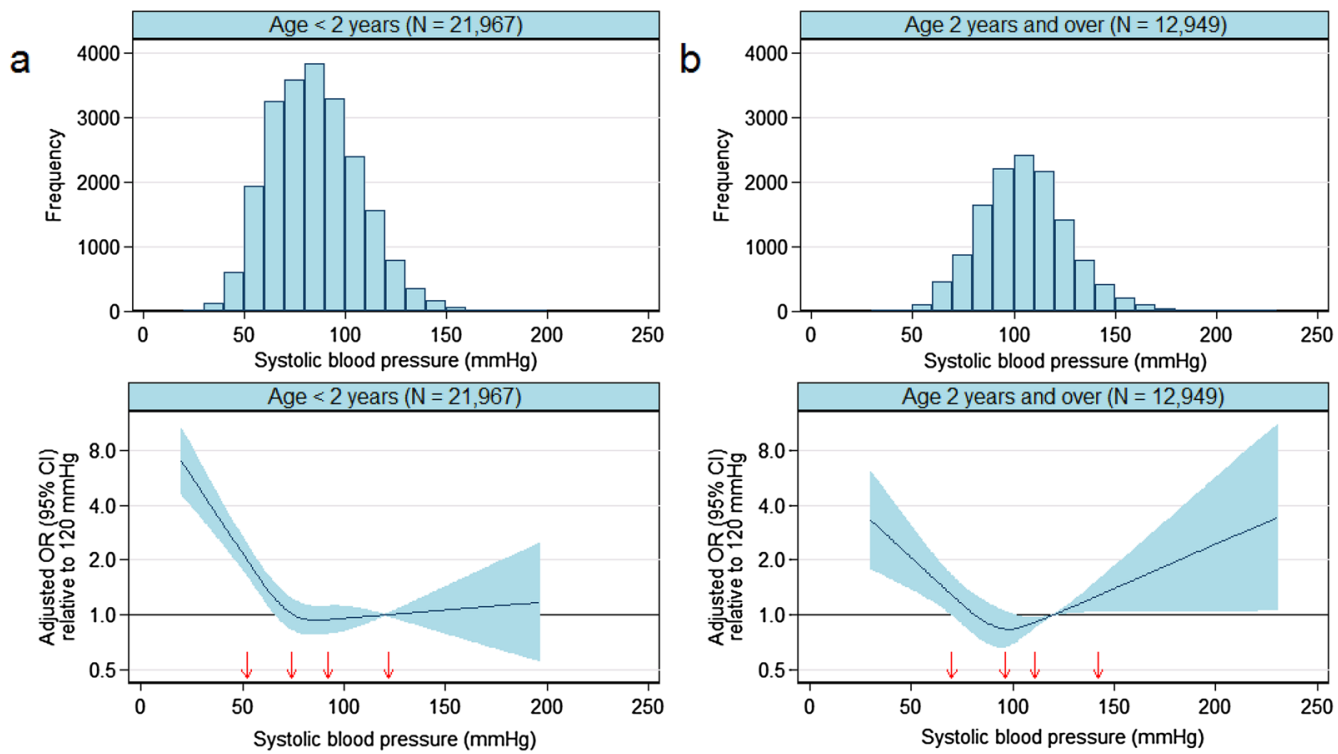

4. The position of the knots in the cubic splines have changed from 51, 74, 91 and 122 to 52, 74, 92 and $122 \mathrm{mmHg}$ in the children $<2$ years and from 70,95 , 112 and 143 to $70,96,111$ and $142 \mathrm{mmHg}$ in children 2 years or older.

5. The sentence 'Expectedly, the risk of death associated with low SBP on admission was greater than with high SBP, especially in children $\geq 2$ years. ' should instead read 'however, for children $<2$ years any increase in mortality at high SBP was minimal.'

6. The statement 'Children $<2$ and $\geq 2$ years show a nadir of risk around the 35th centile SBP for the population'. should read 'Children $<2$ and $\geq 2$ years show a nadir of risk close to the median SBP for the population.'

7. The statement 'However, most children in our cohort had an admission SBP higher than that associated with the lowest risk.' should no longer be considered.

The Authors apologise with the readers for the mistakes.

\footnotetext{
Author details

${ }_{1}^{1}$ Paediatric Intensive Care Unit, Great Ormond Street Hospital NHS Trust, London WC1N 3JH, UK. ${ }^{2}$ Respiratory, Critical Care and Anaesthesia Section, UCL GOS Institute of Child Health, London, UK. ${ }^{3}$ Intensive Care National Audit and Research Network, London, UK. ${ }^{4}$ Cardiac Critical Care, Great Ormond Street Hospital NHS Trust, London, UK. ${ }^{5}$ Paediatric Intensive Care Unit, Royal Brompton and Harefield NHS Foundation Trust, London, UK. ${ }^{6}$ Paediatric Intensive Care Unit, St Mary's Hospital, Imperial College Healthcare NHS Trust, London, UK.
}

Published online: 23 August 2019 